\title{
MACHADO DE ASSIS ENFRENTA TRAGÉDIAS E FARSAS NA CRÔNICA: A REFLEXÃO CRÍTICA DE BONS DIAS!
}

Machado de Assis faces tragedy and delusion in the chronicle: a critical reflection in Bons dias!

\section{Gabriela Kvacek Betella*}

$\mathrm{N}$ as crônicas da série Bons dias! (1888-89), Machado de Assis utiliza uma linguagem tão volúvel e narcísica quanto os níveis de realidade cobertos pela narrativa. É consenso na fortuna crítica machadiana que a materialização dessa relação entre ficção e realidade aparece na prosa do escritor de modo cada vez mais ousado a partir de 1880. A forma da crônica, gênero marcado pela incompletude, pela informalidade e pelo jocoso, se adequa oportunamente à regência das superficialidades, frustrações e narcisismos de uma época: a narrativa passa em revista uma tendência histórica, em suma. No caso de Bons dias!, nota-se um prazer perverso emanando do texto, principalmente quando este vira pelo avesso os conceitos mais "elevados", como o de liberdade ("Todas as liberdades são irmãs; parece que, quando uma dá rebate, as outras acodem logo"), ${ }^{1}$ e os mais cotidianos, como a importância do tempo ("Ainda não vi astrônomo que, metendo a mão no bolso, não trouxesse pegados aos dedos uns dez mil anos pelo menos. Como lhes devem parecer ridículas as nossas semanas!") (p. 110).

* Universidade de São Paulo / Fapesp.

1 MACHADO DE ASSIS, Joaquim Maria. Bons dias! São Paulo: Hucitec/Unicamp, 1990, p. 132. Ed., intr. e notas de John Gledson. Todas as referências às crônicas da série Bons dias! neste trabalho seguem essa edição, apresentando, daqui em diante, apenas a (s) página (s). 
A perversidade das relativizações promovidas pelo discurso é maior quando dirigida aos "tapa-buracos" que mantêm as aparências da sociedade e da política. A leitura que descobre essa direção no relato de Boas noites é é capaz de revelar o oco existente por baixo da tampa. Discurso perverso também é o da "metafísica de quinquilharias"3, no sentido de assimilar uma via de entrada cuidadosa e dar passos atentos, aparentemente dançantes, sobre o chão histórico.

A linguagem das crônicas de Bons dias! é administrada com rigorosa crueldade, porém assumindo a faceta humorística, sinal de um estranhamento sistemático do discurso em relação às notícias comentadas. Boas noites transpõe para o relato uma visão dos acontecimentos, recriando fatos tão pormenorizadamente a ponto de incorporá-los a situações fictícias, como acontece com as intenções da alforria do escravo Pancrácio pelo seu senhor na crônica de 19 de maio de $1888^{4}$ ou com as "questões de federalismo" no diálogo entre um meteoro e o comandante Carvalho no texto de 27 de maio de 1888 . No fundo, a malignidade e a frieza emanadas da leitura confirmam uma "escapada" à constrangedora ética burguesa em vigor no Brasil desde épocas mais remotas.

Um real meteorito descoberto no final do século XVIII no rio Bendegó (Bedengó ou Bendengó, conforme as variações aceitas), no sertão da Bahia, é personagem na crônica de 27 de maio de 1888. Por essa época, a rocha foi transportada a Salvador com muitos imprevistos e, em seguida, ao Rio de Janeiro (para o Museu Nacional). A saída da capital da província foi atrasada por uma convocação extraordinária da Câmara dos vereadores, na tentativa de impedir o transporte da pedra de Bendegó para a Corte, mas a maioria votou contra o embargo, tendo apenas dois vereadores se pronunciado a favor. A travessia do sertão baiano e

2 "Boas noites" é a expressão de despedida em cada crônica de Bons dias!, sendo, portanto, a assinatura daquele que supostamente observa o cotidiano dos anos 1888-89 na cidade do Rio de Janeiro e conversa, na maioria das vezes, com um provável interlocutor. No caso, trata-se respectivamente de um narrador de crônica e qualquer leitor de jornal (A Gazeta de Notícias). Esse narrador da série Bons dias! é um ex-relojoeiro que teria desistido da profissão, segundo ele próprio afirma, "cansado de ver que os relógios deste mundo não marcam a mesma hora" (p. 36). "Boas noites" assiste a várias sessões da Câmara de Deputados e observa a vida sociopolítica brasileira com argúcia, ironia e descrédito.

3 A expressão é de ARRIGUCCI JÚNIOR, Davi. Fragmentos sobre a crônica. In: Enigma e comentário. São Paulo: Cia. das Letras, 1987, p. 51.

4 Durante os trabalhos de mestrado, realizei uma análise dessa crônica, parte da minha dissertação $\mathrm{O}$ funcionamento preciso da inteligência em terra de relógios desacertados: a crônica de Machado de Assis em Bons dias!, defendida em 1998 na Faculdade de Filosofia, Letras e Ciências Humanas da USP. A essência desse trabalho sobre a crônica do Pancrácio está em "Uma lição de história do Brasil e de tratamento literário: o capítulo da abolição numa crônica de Machado de Assis". In: REUNIÃO ANUAL DA SBPC, 51., 1999, Porto Alegre. Reunião Anual da SBPC. Porto Alegre: SBPC/PUC-RS, 1999. v. 51. 
a permanência na capital são interrompidas na crônica de Bons dias! para personificar o meteorito e relatar a suposta conversa entre ele e o comandante José Carlos de Carvalho, chefe da expedição que recuperou o Bendegó.

A narrativa atribui à rocha os adjetivos "vagaroso, silencioso e científico" sempre que se refere às ações do meteorito no discurso, oferecendo-lhe, além da personificação, um caráter paciente, reflexivo e perspicaz para aquele que "não retorquia nada" ao saber da causa dos "rumores" de comemoração da abolição, "pois é natural que nas regiões donde veio, tivesse testemunhado muitos cativeiros e muitas abolições". O meteorito questiona o companheiro de jornada e confessa a sua ansiedade em chegar ao Rio, pelos aborrecimentos das "ridículas estradas de ferro", tão lentas e estranhas à "velocidade de mil raios" com a qual se locomovia "lá em cima" (p. 70).

A velocidade de locomoção natural do Bendegó contraposta aos "vagaroso", "silencioso" e "científico" que assumia em terra firme aparenta estar metaforizando a capacidade de adaptação e o comportamento coerente de um sábio naquele ambiente novo. Contudo, o meteorito confessa-se aborrecido, chama as estradas de ridículas e ainda diz que "a jornada é de matar" (p. 71). Há uma superioridade disfarçada pelo próprio discurso por meio do perfil do meteorito e das explicações que justificam a natureza de suas ações. No fundo, o recém-chegado pode ser caracterizado como um exigente pensador preocupado com o seu destino, em primeiro lugar, mas interessado, também, em dar opiniões quase constrangedoras sobre a política constitucional brasileira. Seu interlocutor, o comandante Carvalho, não parece estar à sua altura, conforme se pode constatar nas réplicas estreitas que profere. Esse contraste instiga uma interpretação conclusiva sobre o caráter do "estrangeiro" muito mais sagaz e menos evasivo que o "nativo". Porém a forma narrativa da crônica leva a observações pertinentes relativas à estrutura da série Bons dias!, nas quais prefiro me deter, sem deixar de sucumbir à tentação de interpretar o caráter do forasteiro do meteoro de Bendegó, o seu desempenho no diálogo e a profundidade de suas curtas reflexões.

$\mathrm{Na}$ capital da província, debatia-se, com base no princípio do direito provincial, o destino do meteorito. Ele indaga ao seu companheiro Carvalho a razão dos dois votos a favor do embargo, e ouve como resposta: "Questão de federalismo..." (p. 71). Também ouve uma explicação sobre o sentido dessa palavra, sobre o movimento federalista, e sobre "o fim de adotar a constituição dos Estados Unidos, sem fazer questão do chefe de Estado, que pode ser presidente ou imperador..." (p. 72). Com efeito, a campanha federalista no Brasil alimentou-se da admiração pelo Federalismo da República dos Estados Unidos e adquiriu vigor na década de 1880 . 
O meteorito, "sempre vagaroso e científico, piscou o olho ao Carvalho", confessando que não entendia a suposta adoção da constituição dos Estados Unidos por um governo imperial. Insinua, portanto, que o Brasil deveria antes mudar o regime para pensar no modelo norte-americano. Mas o Carvalho, "cheio de comiseração", explicou-lhe que "as invenções constitucionais não eram para os beiços de um simples meteorólito; que a suposição de que o sistema dos Estados Unidos não comporta um chefe hereditário resulta de não atender à diferença do clima e outras. Ninguém se admira, por exemplo, de que lá se fale inglês e aqui português. Pois é a mesma coisa". Confiou-lhe ainda que as idéias republicanas davam a certeza da República para alguns - inclusive, "se ela já estivesse estabelecida, acabada estaria há muitos anos a escravidão..." (p. 72), conforme um artigo lido para o meteorito.

Sem deixar de rebaixar o estrangeiro, Carvalho busca legitimar a aplicação da constituição americana pelo Brasil baseando-se na desigualdade natural entre os dois países, mas quer reforçar a independência e a consolidação da nação brasileira. Difícil conciliar essas intenções, ainda mais porque ele escolhe mal os parâmetros e evita o questionamento. Se a discussão sobre a saída do meteorito de Salvador tinha um localismo ridículo, também era "questão de federalismo", conforme argumenta o próprio comandante, provavelmente a postos para enlamear uma das campanhas do momento. Federalismo podia, na visão guiada por Carvalho, resumir-se ao direito da província sobre um meteoro. Depois, "sem ocultar nada", fala dos rumores de república "ou coisa que o valha" (p. 72) que andam "no ar", motivo para o intrépido meteoro ironizar, em francês, certainement: "Noire? Aussi blanche q'une altre", rebatido imediatamente por Carvalho, peitando na mesma língua, entendendo ou fingindo entender a ironia como um calembour. Nessa altura do diálogo, os dois interlocutores estão claramente em competição acirrada; só não sabemos se vencerá a ironia analítica de um ou a dissimulação fugitiva de outro.

O meteorito interrompe as "imparciais" considerações do companheiro sobre a república para exemplificar a compatibilidade entre esse sistema e a escravidão. Antes de percorrer os intermúndios, havia sido general no sul dos Estados Unidos, por ocasião da Guerra de Secessão. Lembra-se de que os Estados Confederados redigiram sua constituição com o preâmbulo "A escravidão é a base da constituição dos Estados Confederados", e também de o presidente Lincoln ter declarado que não subia ao poder para abolir a escravidão. Carvalho justifica assim, secamente: "Mas é porque lá falam inglês" (p. 73).

Após reduzir o federalismo e tentar mostrar a coerência do aproveitamento das leis americanas, o comandante insinua seu descrédito no sistema de governo republicano por meio de considerações que o distanciam marcadamente das idéias 
e certezas republicanas. A sua incoerência e parcialidade bem encobertas pelo discurso preciso da crônica admitem a menção moderada da argumentação do artigo da Gazeta Nacional, segundo a qual a república teria abolido a escravidão. A necessidade do federalismo seria atendida com a utilização da constituição americana, justificada graças às diferenças entre os países e pelos boatos sobre a implantação da república, por sua vez, inibidora natural da escravidão. O meteorito, com as suas indagações e apartes bem colocados, quebra, organiza ou atualiza essas relações frouxas.

A necessidade do federalismo mostra-se por meio da extensão e da precariedade do território, bem como da dependência do governo central para tudo. A constituição americana como modelo exigia, pelo menos, a mesma forma de governo aqui, e as diferenças de clima, cultura e qualquer outra justificam o contrário do que o comandante quer justificar. A república era certa àquela altura do século XIX, portanto não fazia sentido esconder o leite e atenuar o desejo por uma república que iria ao encontro dos anseios de expansão de força moral, material e política dos Estados Unidos. O Brasil poderia exercer o papel de colaborador na prática da satisfação desses anseios, ainda que a república mantivesse a escravidão, segundo a amarração dos argumentos em forma de questões e dados proferidos pelo meteorito.

Com a interrupção certeira, ressaltando o princípio sulista, o estrangeiro "viajado" prova a existência do que parecia inconcebível por aqui, como se mostrasse que não há uma ordem nem associação mais correta para se atingir a melhor forma de governo. Por outro lado, também evidencia, de certo modo, a maleabilidade e a autonomia de um sistema confederativo que não vingará para o Brasil naquele fim de império, tendo que esperar a república. Carvalho parece até responder com um ato perlocutório que à primeira vista põe fim ao diálogo. Mas também pode estar insinuando que aqui, em oposição aos Estados Confederados, nem os membros de uma facção falavam a mesma língua. Ou as duas coisas.

Nesse momento, o meteoro fica pensativo, mas dali a um instante desvia-se para a visita do presidente da província. "Cada vez mais vagaroso e científico", adianta-se o meteoro na recepção ao político. A discussão termina com a explicação de Carvalho, marcada pela ambigüidade presente no seu discurso desde o começo. Isso porque ele é um brasileiro que, apesar do cargo, não demonstra conhecer ou se importar com a realidade e as verdadeiras necessidades do país, muito menos na frente de um estrangeiro, para cujos beiços não eram os projetos discutidos na política nacional.

Essa crônica levanta como assuntos principais a escravidão, o federalismo e a república, entrelaçando-os e, ao mesmo tempo, disfarçando-os com os 
questionamentos do meteorito. Por um lado, o delirante prazer diante da lei da abolição, o localismo da província e a influência norte-americana sobre o modelo de constituição são rebaixados à "conversa de meteorito", mas é justamente nela que estão as reações mais instigadoras, irônicas e superiores, sob forma de declarações como esta: "eu não sou doutor constitucional nem de outra espécie, mas palavra que não entendo muito essa constituição dos Estados Unidos com um imperador..." (p. 72), ${ }^{5}$ ou de procedimentos que preferem mudar de assunto a concordar com uma explicação medíocre e evasiva, como acontece após a última justificativa de Carvalho. O silêncio do meteorito e a atitude preocupada e prática ("Vamos recebê-lo") (p. 73) com relação aos rapapés que atrasavam sua ida para o Rio deixam a discussão de lado e finalizam a crônica com pontos a favor do poder de reflexão do estranho.

Por outro lado, não se pode esquecer que os elementos essenciais dessa crônica parente de um conto apóiam-se sobre a ficcionalização fantástica de uma situação, o diálogo entre um "estrangeiro" e um membro da Sociedade Geográfica do Rio de Janeiro. O fantástico assume os riscos das reflexões do meteorito, e também permite o acerto das mesmas, ressaltando o comportamento sábio que transparece das qualidades atribuídas, mas é fundamental observar como o diálogo e as reflexões podem causar descrédito e desânimo sobre as considerações "vagarosas, silenciosas e científicas" incapazes de combater as frases de efeito, os raciocínios simplórios, as explicações furadas, rápidas, pouco científicas. Ao final da crônica, o meteorito revela o interesse pelo seu próprio destino, "vagarosa e cientificamente", assumindo esses procedimentos e, assim, evitando o estrondo, as falácias e a polêmica - coisas que, muito a propósito, devem ter rodeado a queda e o transporte do meteorito.

A crônica assume uma perspectiva simplificadora dos dados da realidade. Elegendo um meteorito caído no Brasil como personagem central, oferecendo-lhe

5 No final da crônica de 11 de junho de 1888, Boas noites volta ao tema, mencionando uma sessão do congresso liberal em São Paulo, no qual se apresentou um projeto de confederação modelada pela dos Estados Unidos, mantendo o Imperador como chefe do poder executivo e o regime parlamentarista, além de se escolherem os presidentes dos Estados pela coroa, a partir de três nomes apresentados pelo legislativo (Cf. Jornal do Commercio, 06 jun. 1888). Considerando tal projeto "assunto superior" à sua capacidade, pondera Boas noites: "Já aqui dei opinião do aerólito de Bendegó, acerca da constituição dos Estados Unidos com chefe hereditário, coisa que ele afirma que é o mesmo que pôr o chefe do Estado em terra. Agora adotou-se o mesmo projeto, com esta cláusula: que continuará o sistema parlamentar. Quando li isto a um amigo, vi-o ficar de boca aberta, e não entendi o motivo; agora mesmo, que ele me explicou o negócio, confesso que estou in albis. Diz ele (jurou-me por Deus nosso senhor) que o característico principal da constituição dos Estados Unidos é ser justamente o avesso do sistema parlamentar; a união dos dois parece-me uma cobra casada com um rato, segundo disse um poeta." (p. 80) 
voz, movimentos e poder de questionamento e de reflexão requintado, a narrativa se preocupa com as vantagens do meteoro sobre os homens. Não é à toa que o narrador menciona a possibilidade de o estranho ter "testemunhado muitos cativeiros e muitas abolições", a sua anterior "velocidade de mil raios" (p. 70), o seu julgamento sobre os "homens cruéis" (p. 71) que tentaram embargar a sua saída da Bahia, o seu estranhamento diante da constituição e assim por diante. A pedra de Bendegó vem de regiões distantes, das quais pouco se sabe. Esta noção é muito clara para o narrador, quando ele atira a dúvida "Quem sabe lá o que vai pelos vastos intermúndios de Epicuro e seus arrabaldes?" (p. 70). O que sobra no meteoro e existe em certa medida no narrador parece faltar aos acontecimentos brasileiros que são assuntos da crônica: a capacidade de dimensionar as questões nacionais, incluindo sempre suas causas e conseqüências.

Na crônica de 19 de julho de 1888, Boas noites chega a lamentar não ser "bei de Túnis" (p. 96). Segundo nos faz entender, uma das grandes vantagens de se viver em Túnis seria a cordialidade estabelecida, graças ao fato de não se entender o que dizem os habitantes de lá, e vice-versa. O Rio de Janeiro estaria presente, pois Boas noites assinaria jornais e leria todos os artigos, das contendas aos debates parlamentares e manifestos políticos. Assim, algumas "pérolas" brasileiras não perderiam o valor naquela terra distante, mesmo o que viesse dito ou escrito "em dialeto barbaresco" (p. 96), pois o colégio de intérpretes trataria de verter o conteúdo dos jornais.

Haveria muitos fatos do Brasil a serem explicados pelos intérpretes em Túnis naqueles dias, como a farsa do médium norte-americano chamado Dr. Slade, que andou por aqui. Investigados os "fenômenos" pela Federação Espírita Brasileira, não houve o que "o homem valesse a fama", então a Federação explicou que "as mediunidades estão sujeitas a esses eclipses" e "os invisíveis não estão servilmente à nossa disposição". Com uma espécie de lamento, desejando fugir ao alcance da "porção de coisas abstrusas" (p. 98) com a nomeação em Túnis, porém descrevendo uma atitude muito comum, verdadeiro motivo da "fuga", Boas noites encerra a crônica:

\footnotetext{
"Que porção de coisas abstrusas, que eu nunca hei de entender! E daí, quem sabe? Schopenhauer chegou a crer nas mesas que giram; há quem acredite no casamento da constituição americana com o sistema parlamentar. Não é muito acreditar nos motivos do eclipse do Dr. Slade, mesmo sem entendê-los... Ah! Porque me não fazem bei de Túnis!” (98-9)
} 
Denunciando o mau hábito de acreditar naquilo que não é entendido, Boas noites também define a sua situação imaginária de alto funcionário otomano, na qual não entenderia ninguém, nem os outros o entenderiam, e daí surgiriam as relações mais cordiais, assim como surgira a amizade entre Von Stein e os índios do Xingu. Com sutileza, o narrador está fustigando leitores a prestarem mais atenção em verdades e anormalidades cordialmente aceitas, cujo fundo nebuloso não é bem entendido. Impiedoso, ele aponta a normalidade dessa atitude generalizada aqui e amplia os horizontes do absurdo, levando-o para além-mar - em Túnis ele também pareceria crédulo, embora pudesse questionar melhor os contrastes, talvez devido à distância necessária à análise.

Em 16 de setembro, Boas noites retorna de uma série de espetáculos teatrais promovidos em benefício do "incidente Manso" - episódio iniciado com a recusa do deputado republicano Monteiro Manso em prestar juramento à coroa ao tomar posse, resultando dias de debates da Câmara. O narrador critica a extensão das peças, explicando a causa - "Verdade é que, sendo numerosos os amadores, todos quereriam algum papel (...)" - e oferece a solução mais prática:

O remédio era o fonógrafo, com os aperfeiçoamentos últimos que the deu o famoso Edison. Fez-se agora a experiência em Londres, onde por meio do aparelho se ouviram palavras, cantigas e risadas do próprio Edison, como se ali estivesse ao pé. Um dos jornais daquela cidade escreve que o fonógrafo, tal qual está agora aperfeiçoado, é instrumento de duração quase ilimitada. Pode conservar tudo. Justamente o nosso caso.

Acabada a representação, em pouco tempo, segundo convinha à urgência e gravidade do assunto e do momento, se ainda houvesse amadores que quisessem um papel qualquer, grande ou pequeno, o diretor faria distribuir fonógrafos, onde cada um daqueles depositaria as suas idéias; podiam ajustar-se três ou quatro para os diálogos.

A reprodução de todas as palavras ali recolhidas podia ser feita, não à vontade do autor, mas vinte e cinco anos depois. Ficavam só as belezas do discurso; desapareciam os inconvenientes. (p. 117-18)

Além de servir à comunidade teatral e, especialmente, à paciência dos espectadores, o fonógrafo de Thomas Edison seria o remédio perfeito para "um dos males do sistema parlamentar: o abuso da palavra." Seriam escolhidos alguns 
oradores para falar sobre cada "negócio"; os que sobrassem "confiariam ao fonógrafo os discursos que a geração futura escutaria", por exemplo, no ano de 1913, quando os fonógrafos se abririam para a voz de algum orador discutir "o orçamento da receita geral do império" (118), com um magnífico discurso cheio de digressões. Assim, os discursos que em 1888 não eram lidos "chegariam à posteridade com a frescura da própria cor do orador" (p. 119).

Novamente, vemos o narrador de Bons dias! provocando o leitor e os fatos consumados de seu tempo. Por trás desse tipo de inconformismo que anseia a transmissão, há algumas ironias sutis que não param na sugestão do simples emprego do fonógrafo. Mencionando a invenção do americano cujos experimentos obtiveram efeitos práticos de alto valor comercial, Boas noites aponta o outro lado desse proceder científico: a descoberta da tecnologia ou "ciência aplicada". A ironia está no emprego da última palavra em tecnologia para armazenamento de mesquinharias ou auto-elogios. Assim como Edison fez surgir novo conhecimento a partir de seus experimentos de objetivo prático, Boas noites pode, com sua ironia dirigida, levar o leitor ao conhecimento de uma realidade cansativa, atrasada e retrógrada. Além disso, deixando o fardo dos discursos gravados para os estudiosos do futuro sociologistas, lingüistas, cronistas - admite que haverá vantagem "para todos", “começando talvez por nós - ingratos!” (p. 119).

Por vezes a manipulação da linguagem em Bons dias! assume, ao invés da crueldade, um abatimento moral capaz de produzir efeitos mais graves durante a leitura, deslocando as "atrocidades" exclusivamente para os fatos comentados. O narrador escapa novamente, deixando para si a depressão, a tristeza diante das suas constatações. Assim se comporta a crônica de 25 de novembro de 1888, trazendo denúncias e relações intertextuais muito interessantes. O texto refere-se à falsificação dos comestíveis, aos crimes (assassinatos, desaparecimentos), às doenças (a peste dos burros, a febre amarela), à seca do Ceará (a pior desde 1877), às religiões "clandestinas", expressando imediatamente na abertura o aborrecimento do narrador e as contradições da sociedade:

\footnotetext{
"Nunca tirei o chapéu com tanta melancolia. Tudo é triste em volta de nós. A própria risada humana parece um dobre de finados. Creio que somos chegados ao fim dos tempos.

Não faltam banquetes, é verdade; mas, pergunto eu, que é que se come nesses banquetes, estando tudo falsificado?” (p. 138).
} 
BETELLA, G. K. Machado de Assis enfrenta tragédias e farsas...

A denúncia sutil do comportamento superficial explorando as diferenças é, no fundo, muito séria, ainda que o narrador despiste, empregando as meias tintas propositadamente, a fim de se confundir com os que freqüentam os banquetes e fingir total desconhecimento sobre os "conselhos à pena amiga". ${ }^{6}$

A minha pena parece-se com um cachorrinho que me doaram; quando lhe dá para correr, tão depressa está em casa como nas pontas da lua. Não tem juízo esta pena. Não obedece a posturas, nem às leis, nem a nada; anda, desanda, tresanda. Creiam-me; não me faltam idéias sublimes; falta-me pensar como que as fixe no papel. (p. 139)

Levando em conta a melancolia exposta no início da crônica, essa última frase assume um tom desmotivado com a própria capacidade discursiva. Ao mesmo tempo, toda a passagem acima representa o comportamento "distraído" identificando o narrador com os privilegiados, desatentos às causas das diferenças na sociedade, porém preocupados demais com o capricho de "comentar" os abusos.

Na segunda parte da crônica, Boas noites muda de assunto, oferecendo uma interpretação particular sobre os episódios conhecidos como movimento pelo "fechamento das portas". ${ }^{7}$ As contradições não são poupadas do enfrentamento bemhumorado do narrador:

6 Num texto de 1863 , a contenção do texto de crônica é proclamada pelas metáforas que prenunciam comportamentos futuros, inclusive o tão comentado "tédio à controvérsia" do Conselheiro Aires, quase prevenindo o leitor: "Antes de começarmos o nosso trabalho, ouve, pena amiga, alguns conselhos de quem te preza e não te quer ver enxovalhada. Não te envolvas em polêmicas de nenhum gênero, nem políticas, nem literárias, nem quaisquer outras; de outro modo verás que passas de honrada a desonesta, de modesta a pretensiosa, e em um abrir e fechar de olhos perdes o que tinhas e o que eu te fiz ganhar. $\mathrm{O}$ pugilato das idéias é muito pior que o das ruas; tu és franzina, retrai-te na luta e fecha-te no círculo dos teus deveres, quando couber a tua vez de escrever crônicas. Sê entusiasta para o gênio, cordial para o talento, desdenhosa para a nulidade, justiceira sempre, tudo isso com aquela meia tinta, tão necessária para os efeitos da pintura... Comenta os fatos com reserva, louva ou censura como te ditar a consciência, sem cair na exageração dos extremos. E assim viverás honrada e feliz." MACHADO DE ASSIS, Joaquim Maria. Obras completas. Rio de Janeiro: W. M. Jackson, 1950, v. 22, p. 299-300.

7 Boas noites já se referia ao movimento nas crônicas de 16 de setembro e 10 de novembro. Os jornais da época comentavam as manifestações a favor da redução das horas de trabalho das casas de comércio (que não fechavam nem aos domingos) associando-as à violência dos caixeiros manifestantes. É oportuno observar a direção do comentário do narrador nesta crônica de 25 de novembro, encerrando o seu parecer sobre aqueles fatos com uma reflexão sobre as manifestações de caráter revolucionário. 
Uma senhora ingênua, quando há tempo houve um barulho na rua, por causa de portas abertas, ao ler que um ferido foi levado à farmácia, perguntou-me:

- Mas se as portas das farmácias já estivessem fechadas? (p. 140)

Essa passagem relativiza o movimento, prevenindo o leitor para a parcialidade - e, portanto, para a deficiência - do caráter revolucionário; também faz um preâmbulo para a relativização mais profunda do texto, no último parágrafo, apoiada no sentido mais geral da análise de Karl Marx sobre os acontecimentos revolucionários franceses de $1848-1851:^{8}$

Que este movimento liberal e generoso assuste a alguns, é natural. Assim é que um amigo meu, negociante de trastes velhos, diziame há dias que talvez chegasse o tempo em que ele e os colegas tenham de fazer um movimento igualmente liberal para obter a abertura de portas, aos sábados, por exemplo. A reflexão é grave, como se vê, mas nem por isso há de atar as mãos ao atual movimento. Façam primeiro 89; os ferros-velhos que tragam o 18 Brumário. (p. 140)

Boas noites encara com muita naturalidade, certeza e gravidade a reflexão sobre a possível reação, no futuro, de alguns negociantes, numa tentativa de "abertura de portas". A agitação recente, para o "fechamento", seria o "89" - e 1889 era o ano que já estava a caminho -, numa alusão clara ao movimento francês cujo ápice foi

8 Em O 18 Brumário de Luís Bonaparte, obra à qual Machado se refere implicitamente nesta crônica, Marx expõe e desenvolve todas as teses fundamentais do materialismo: teoria da luta de classes e da revolução proletária, doutrina sobre o Estado e a ditadura do proletariado. As conclusões, nada animadoras, apontam para as atitudes do proletariado em relação ao Estado burguês: "Todas as revoluções políticas apenas aperfeiçoaram essa máquina, em vez de a destruir.” Brumário é o segundo mês do calendário republicano francês. A obra $O 18$ de Brumário... (9 de novembro) de 1799, Napoleão executou um golpe de Estado que derrubou o Diretório, e instalou sua ditadura. Marx menciona uma "segunda edição de $O 18$ de Brumário", aludindo ao golpe de Estado contra-revolucionário de 2 de dezembro de 1851, perpetrado por Luís-Napoleão e seus partidários. Segundo Marx, tratava-se de um resultado natural e necessário dos acontecimentos, e seu "herói" não merecia tratamento destacado. Ver MARX, Karl. O 18 Brumário de Luís Bonaparte. Tradução: Maria Flor Marques Simões. São Paulo: Mandacaru, 1990. 
1789. ${ }^{9}$ A suposta reação liderada pelos negociantes de ferro-velho seria o "18 Brumário". Esta relação aponta a feição reacionária, golpista e fruto de "89", e a utilização dos "ferros-velhos" como protagonistas não é casual, pois indica a persistência da pior face das reivindicações, a farsa, talvez. ${ }^{10}$ No fundo, Boas noites insinua que a força de novidade das "revoluções" tende ao enfraquecimento, favorecendo a reação. Acredito que Boas noites foi capaz de antever no comércio do Rio, como Marx na França operária, uma "segunda edição" do "18 Brumário".

Quando visualizamos esse diálogo estabelecido entre Bons dias! e uma das principais obras do marxismo, um dos fatores que se destacam é uma espécie de "pretensão" na crônica de um ex-relojoeiro carioca. Nota-se uma comparação entre os acontecimentos de França e Rio de Janeiro, bem como uma intenção de teorização crítica sobre as turbulentas reivindicações do comércio carioca. Se for verdade que Machado empreendia um processo de relativização amplo ao contrastar matérias que alcançaram altitude na tradição literária com os enredos desenvolvidos a partir da realidade urbana brasileira do século XIX, ${ }^{11}$ também é possível afirmar que a crônica lhe forneceu o terreno certo para unir, por meio dos comentários de um narrador atrevido, rebarbas de teorias socioeconômicas globais às reflexões sobre o dia-a-dia da acanhada capital do Império Brasileiro. Nesse sentido, a crônica propicia ao leitor uma "tradução" dos resultados da conceituada análise marxista através da despretensiosa profecia anunciada para o caráter liberal das manifestações por direitos de trabalho. Transparece desse procedimento um desejo de "atualização" da teoria pela sua aplicação, noutras palavras, o "original" é atualizado pela

9 De Marx: "O período de 1848 a 1851 apenas evocou o espectro da grande Revolução Francesa, desde Marrast, o republicain en gants jaunes, que se disfarça de Bailly, até o aventureiro que dissimula os seus traços vulgares e repulsivos sob a máscara mortuária de ferro de Napoleão. Todo um povo que julga que a si próprio deu, por meio de uma revolução, uma maior capacidade de movimento acha-se bruscamente transportado para uma época abolida e, para que nenhuma ilusão sobre essa regressão seja possível, reaparecem as datas antigas, o calendário antigo, os nomes antigos, os antigos éditos há muito matéria de eruditos e de antiquários e todos os velhos esbirros que já há muito pareciam ter entrado em decomposição." MARX, op. cit., p. 19-20.

10 Tendo ficado bastante conhecida pela originalidade, a abertura do texto de Marx cita Hegel: "Hegel faz notar algures que todos os grandes acontecimentos e personagens históricos se repetem por assim dizer uma segunda vez. Esqueceu-se de acrescentar: da primeira vez como tragédia, da segunda como farsa." (MARX, op. cit., p. 17) Vale lembrar que a idéia de história como manifestação cíclica já esteve relacionada a Machado de Assis.

11 O ensaio fundamental para o entendimento desse método machadiano, embora voltado para os contos, é de VILLAÇA, Alcides. Machado de Assis, autor de si mesmo. Novos Estudos CEBRAP, n. 51, p. 3-14, jul. 1998. 
"tradução", destacando o contraste, marcando o desnivelamento entre ambos. Os contextos de Marx e Boas noites são comparáveis, mas o do segundo acaba rebaixado a uma condição menor, de menos relevância, de maior vulgaridade.

A habilidade de alguns narradores machadianos em "traduzir" passagens de outros autores para a trama de contos e romances ou para o comentário da crônica denota grande parte da modernidade literária das obras de Machado. Boas noites desmascara várias atitudes de seu tempo elevando um fato para poder destruí-lo. Dizendo de outro modo, o narrador machadiano acaricia para poder bater, engrandece um acontecimento para mostrar sua insignificância ou, ainda, permite a exposição exagerada de figuras e fatos do meio político, o suficiente para se ridicularizarem.

A confusão política formadora do contexto de Bons dias! refletia-se no plano das idéias, e essa relação persistiu na vida brasileira. A maior "crueldade" das crônicas da série é a frieza da análise sobre as conseqüências do pacto liberal-conservador, cujos momentos-chave são 1870 e 1888-89. A leitura dessas crônicas em nossos tempos de reedição bem mais sofisticada de coalizão liberal-conservadora admite uma confirmação de profecias relativas aos efeitos das espertas alianças. As palestras do ex-relojoeiro oitocentista levam à dedução de uma antevisão pouco animadora, sobretudo no que diz respeito à banalização ou ao fim de uma crítica efetiva partindo do meio intelectual, à defesa das forças sociais e políticas das velhas oligarquias pelos governos e à adesão da sociedade ao consenso de real fundo conservador.

Bons dias! representa uma luta pela validade da crítica sem ardores, sem declarada oposição ou adesão às novas feições político-econômicas. Todas as sutilezas da composição, do perfil do narrador às piadas sobre atos políticos ou privados permanecem como observação atenta contra o consenso que então se estabelecia e declarava um futuro regrado pelo conservadorismo, disfarçado ou não, hábil em cooptar inclusive as manifestações intelectuais com "espírito de oposição histórica". As crônicas de Machado de Assis demonstram uma consciência do caráter cíclico e repetitivo da história, incluindo a repetição do movimento de "cooptação pela direita" ou de "migração da "esquerda" no cenário político-social brasileiro. É bem verdade que as teses, as deduções e o dogmatismo conservadores seriam atualizados, isto é, os produtos dos pactos liberais-conservadores seriam "readequados", na medida em que atendessem aos interesses tecnocráticos de poder.

Sem aderir ao "pugilato das idéias", mantendo o "entusiasmo para o gênio", a "cordialidade para o talento", o "desdém pela nulidade" e a justiça, a pena de Machado na crônica sustentou os conselhos que o cronista elaborou nos anos 60, numa espécie de leitura antecipada da própria obra. A "meia tinta, tão necessária para os efeitos da pintura", foi o veículo para o comentário reservado, sem a "exageração dos extremos". O texto obteve permissão para revelar problemas e representá-los por meio do efeito dos seus caracteres peculiares num movimento 
correspondente à ação do pintor com a tinta - ou "meia tinta" - utilizada. Visualizar esse movimento embutido no texto é estabelecer o ponto de partida para a composição do perfil do narrador da crônica, como também é definir as origens dos condutores das obras machadianas de fundo memorialístico.

\section{RESUMO}

O trabalho explora algumas passagens de crônicas da série Bons dias!, escrita por Machado de Assis entre 1888 e 89, publicada na Gazeta de Notícias. A proposta é elucidar a capacidade de relativização do texto machadiano na crônica, estratégia fundamental para determinar a profundidade da reflexão crítica oferecida ao leitor Palavras-chave: Machado de Assis, crônica, narrador.

\section{ABSTRACT}

This work explores some passages of chronicles of the series Bons dias!, written by Machado of Assis between 1888 and 89, published in the Gazeta de Notícias. The proposal is to elucidate the relativism of the machadian text in the chronicle, fundamental strategy to determine the depth of the critical reflection offered to the reader.

Key-words: Machado de Assis, chronicle, narrator.

\section{REFERÊNCIAS}

ARRIGUCCI JÚNIOR, Davi. Fragmentos sobre a crônica. In: Enigma e comentário. São Paulo: Cia. das Letras, 1987, p. 51.

BETELLA, Gabriela Kvacek. O funcionamento preciso da inteligência em terra de relógios desacertados: a crônica de Machado de Assis em Bons dias! São Paulo, 1998. Dissertação (Mestrado em Literatura Brasileira - Faculdade de Filosofia, Letras e Ciências Humanas da USP.

BETELLA, Gabriela Kvacek. Uma lição de história do Brasil e de tratamento literário: o capítulo da abolição numa crônica de Machado de Assis. In: REUNIÃO ANUAL DA SBPC, 51., 1999, Porto Alegre. Reunião Anual da SBPC. Porto Alegre: SBPC/Puc-RS, 1999. v. 51. CD-ROM.

MACHADO DE ASSIS, Joaquim Maria. Bons dias! São Paulo: Hucitec/Unicamp, 1990. Ed., intr. e notas de John Gledson. 
BETELLA, G. K. Machado de Assis enfrenta tragédias e farsas...

MACHADO DE ASSIS, Joaquim Maria. Obras completas. Rio de Janeiro: W. M. Jackson, 1950, v. 22.

MARX, Karl. O 18 Brumário de Luís Bonaparte. Tradução: Maria Flor Marques Simões. São Paulo: Mandacaru, 1990.

VILLAÇA, Alcides. Machado de Assis, autor de si mesmo. Novos Estudos CEBRAP, São Paulo, n. 51, p. 3-14, jul. 1998. 